\section{BRAZIULIAN JOURNAL \\ OF MEDICAL AND BIOLOGICAL RLSF.ARCH}

www.bjournal.com.br
ISSN 0100-879X

Volume 42 (11) 993-1118 November 2009

BIOMEDICAL SCIENCES

AND

CLINICAL INVESTIGATION

Braz J Med Biol Res, November 2009, Volume 42(11) 1020-1026

Dengue virus-induced regulation of the host cell translational machinery

C.S.A. Villas-Bôas, T.M. Conceição, J. Ramírez, A.B.M. Santoro, A.T. Da Poian and M. Montero-Lomelí

The Brazilian Journal of Medical and Biological Research is partially financed by
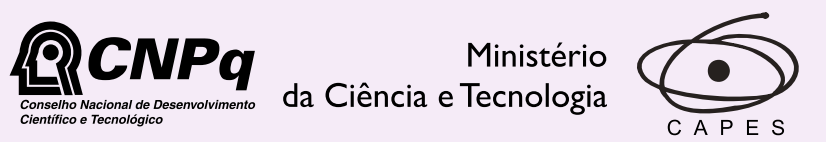

Ministério da Educação

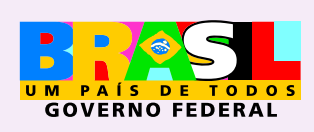

DFAPESP

Institutional Sponsors 


\title{
Dengue virus-induced regulation of the host cell translational machinery
}

\author{
C.S.A. Villas-Bôas ${ }^{1}$, T.M. Conceição ${ }^{1}$, J. Ramírez², A.B.M. Santoro¹, \\ A.T. Da Poian ${ }^{1}$ and M. Montero-Lomelí ${ }^{1}$ \\ ${ }^{1}$ Programa de Biologia Molecular e Biotecnologia, Instituto de Bioquímica Médica, \\ Universidade Federal do Rio de Janeiro, Rio de Janeiro, RJ, Brasil \\ ${ }^{2}$ Departamento de Genética Molecular, Instituto de Fisiologia Celular, \\ Universidad Nacional Autónoma de México, Mexico City, Mexico
}

\begin{abstract}
Dengue virus (DV)-induced changes in the host cell protein synthesis machinery are not well understood. We investigated the transcriptional changes related to initiation of protein synthesis. The human hepatoma cell line, HepG2, was infected with DV serotype 2 for $1 \mathrm{~h}$ at a multiplicity of infection of one. RNA was extracted after 6,24 and $48 \mathrm{~h}$. Microarray results showed that $36.5 \%$ of the translation factors related to initiation of protein synthesis had significant differential expression (Z-score $\geq$ \pm 2.0 ). Confirmation was obtained by quantitative real-time reverse transcription-PCR. Of the genes involved in the activation of mRNA for cap-dependent translation (elF4 factors), elF4A, elF4G1 and elF4B were up-regulated while the negative regulator of translation elF4E-BP3 was down-regulated. This activation was transient since at $24 \mathrm{~h}$ post-infection levels were not significantly different from control cells. However, at $48 \mathrm{~h}$ post-infection, elF4A, elF4E, elF4G1, elF4G3, elF4B, and elF4E-BP3 were down-regulated, suggesting that cap-dependent translation could be inhibited during the progression of infection. To test this hypothesis, phosphorylation of p70S6K and 4E-BP1, which induce cap-dependent protein synthesis, was assayed. Both proteins remained phosphorylated when assayed at $6 \mathrm{~h}$ after infection, while infection induced dephosphorylation of p70S6K and 4E-BP1 at 24 and $48 \mathrm{~h}$ of infection, respectively. Taken together, these results provide biological evidence suggesting that in HepG2 cells DV sustains activation of the cap-dependent machinery at early stages of infection, but progression of infection switches protein synthesis to a cap-independent process.
\end{abstract}

Key words: Dengue virus; Flavivirus; Protein synthesis

\section{Introduction}

Dengue virus (DV), an RNA virus member of the Flaviviridae family, is one of the major human arboviruses in the world, whose clinical manifestations range from a mild self-limited fever to severe and potentially life-threatening diseases such as dengue hemorrhagic fever and dengue shock syndrome (1). The virus is transmitted to humans through the bite of mosquitoes of the genus Aedes infected by one of the four serotypes of the virus and it is estimated that 2.5 billion people live in risk areas and 50-100 million infections occur annually, leading to about 20 thousand deaths $(2,3)$.

Although the clinical manifestations of dengue hemorrhagic fever/dengue shock syndrome have been well described, the limited understanding of the molecular mechanisms involved in the interactions between DV and its host cells is one of the causes of the lack of adequate therapeutic approaches to DV-caused diseases. One interesting point in the life cycle of RNA viruses is that

Correspondence: M. Montero-Lomelí, Programa de Biologia Molecular e Biotecnologia, Instituto de Bioquímica Médica, UFRJ, Caixa Postal 68041, 21941-590 Rio de Janeiro, RJ, Brasil. Fax: +55-21-2270-8647. E-mail: montero@bioqmed.ufrj.br

Research supported by ICGEB-OPS-RELAB Collaborative Research Programme; Rede Genoprot-Dengue MCT/FINEP; FAPERJ Pensa Rio e Cientistas do Nosso Estado; CNPq to M. Montero-Lomelí and to A.T. Da Poian. C.S.A. Villas-Bôas was the recipient of an undergraduate fellowship and presently of a Master's degree from CNPq, and T.M. Conceição and A.B.M. Santoro are recipients of doctoral fellowships from CNPq.

This study is dedicated to the memory of our student Taiane Monteiro de Lima and to her colleagues at the Universidade Federal do Rio de Janeiro who will remember her always and will accomplish a fruitful career in Nursing.

Received January 19, 2009. Accepted September 1, 2009. Available online October 26, 2009. 
they have evolved several strategies for expressing their own proteins inside the host cell by modulating cellular transcription and translation. DV-RNA is a single-stranded positive sense molecule that contains an $\mathrm{m} 7 \mathrm{G}\left(5^{\prime}\right) \mathrm{pppG}\left(5^{\prime}\right)$ $\mathrm{N}$-cap structure (cap structure) at the 5'end and a 3'stem loop of 100 nucleotides, instead of the polyadenylation tail of cellular mRNA (4). Its translation results in a large polyprotein that is processed co- and post-translationally by proteases into at least 10 viral proteins, 3 structural (C, prM and $\mathrm{E}$ ) and 7 non-structural proteins (NS1, NS2A, NS2B, NS3, NS4A, NS4B, and NS5). Despite the progress in the understanding of flavivirus translation strategies, the complete understanding of how DV interacts with the host cell translational machinery is still lacking.

The initiation of translation is the most crucial step for regulation of protein synthesis in eukaryotic cells. During this step it is essential to activate the mRNA by elF4 factors. The 5 '-cap structure of the mRNA is recognized by elF4E, which is part of the complex known as elF4F, formed by elF4E, an RNA helicase, elF4A and an adaptor protein, elF4G (5). The mRNA is thought to be circularized by interaction of elF4G with the poly $(A)$ binding protein, which in turn interacts with the poly(A) tail (6). The ribosomal $40 S$ subunit carrying tRNA-Met/elF2-GTP then binds to this structure recognizing the initiation codon $A \cup G$. Afterwards the 605 subunit binds to this complex forming monosomes 805 (5). Positive regulation of the formation of the initiation complex occurs mainly by regulation of elF4E at the transcription level (7) and by inhibition of elF4E interaction with $4 \mathrm{E}$ binding proteins (4E-BPs) by hyper-phosphorylation of the latter $(8,9)$. Ribosomal protein S6 (RPS6) in its phosphorylated form has also been linked to stimulation of translation. S6 is phosphorylated by the p70S6K, which is in turn regulated positively by phosphorylation. Both 4E-BP1 and p70S6K are regulated by two pathways that sense nutrients activating them $(10,11)$. These pathways are phosphoinositide 3' kinase, protein kinase $\mathrm{B}$ (PKB or AKT) and the mammalian target of rapamycin, mTOR (12). Eukaryotic cells also rely on a cap-independent mechanism of translation, or internal ribosome entry site (IRES)-mediated translation initiation, which was discovered when the interaction of poliovirus with the cellular translation machinery was studied (13). Poliovirus inhibits translation by selectively inhibiting the cap-dependent translation by degrading elF4G and sequestering elF4E protein that leads to the important switch from expression of cellular proteins to expression of viral proteins (14). However, each virus induces different changes in the cell translational machinery to promote IRES-mediated translation initiation.

DV does not inhibit host protein translation but interacts with the cap-dependent machinery through its 5 'cap structure (15). The flavivirus RNA also binds viral non-structural proteins NS5, NS3 and NS2A and the cellular proteins eEF1A, La and PTB (16). It has been recently shown that inhibition of the cap-dependent machinery either by suppression of EIF4E expression or by the addition of the inhibitors LY294002 and wortmanin does not inhibit replication and translation of DV, suggesting that translation occurs via a cap-independent mechanism. However, the DEN-5'UTR region does not contain an IRES that could recruit the protein synthesis machinery. The authors suggest that probably interactions between the 5' and 3'UTR sites promote this interaction (17).

The main objective of the present study was to characterize how DV interacts with the host cell translational machinery. We used HepG2, a human hepatoma cell line, to follow post-infection changes in the expression of genes involved in the protein synthesis machinery assayed by global gene expression and quantitative real-time PCR (qRT-PCR). The choice of using HepG2 cells was based on the fact that liver dysfunction is a characteristic of severe dengue infection (18). Analyses of liver autopsies obtained from individuals with dengue hemorrhagic fever have revealed extensive areas of tissue damage, with foci of necrosis, steatosis and apoptosis, characterized by the presence of apoptotic bodies $(19,20)$. Viral antigens were detected near the lesioned areas, suggesting an association between virus replication and hepatic damage. Hepatomegaly (21), liver enzyme abnormality (21-24) and occasional fulminant hepatic failure $(25,26)$ also illustrate the influence of DV infection on liver function. During the early phase of infection, DV activates the cap-dependent protein synthesis machinery in which transcription of genes involved in mRNA activation are transiently up-regulated and the regulators of translation 4E-BP1 and $\mathrm{p} 70 \mathrm{~S} 6 \mathrm{~K}$ are in the phosphorylated state. However, the progression of infection leads to the inhibition of the transcription of essential genes related to the cap-dependent machinery and of ribosomal genes. Accordingly, 4E-BP1 and p70S6K are dephosphorylated. The results suggest that DV maintains the cap-dependent translation machinery active at early times of infection and progression promotes its inhibition.

\section{Material and Methods}

\section{Cell culture and virus propagation}

HepG2 cells were acquired from the American Type Cell Collection (USA). Cells were cultured on appropriate medium (minimum essential medium with $5 \mathrm{mM}$ glucose) supplemented with $10 \%$ fetal bovine serum (Invitrogen Corporation, USA), $100 \mathrm{U} / \mathrm{mL}$ penicillin, $100 \mu \mathrm{g} / \mathrm{mL}$ streptomycin, $0.22 \%$ sodium bicarbonate, and $0.2 \%$ HEPES, $\mathrm{pH}$ 7.4 , in a $\mathrm{CO}_{2}$ humid incubation chamber at $37^{\circ} \mathrm{C}$. HepG2 is a differentiated human hepatocellular carcinoma cell line, which preserves many of the morphological and functional characteristics of hepatocytes (27-29). Cells were seeded at a density of $4 \times 10^{5} \mathrm{cells} / \mathrm{mL}$, and grown on plastic Petri dishes. At $70 \%$ confluence, cells were either mock-infected or infected with DV serotype 2 Asiatic strain 16681 (mul- 
tiplicity of infection of 1 plaque forming unit per cell). After $1 \mathrm{~h}$, cells were washed to remove non-adsorbed viruses and incubated with $10 \mathrm{~mL}$ of growth medium for the desired periods of time.

DV was propagated in C6/36 Aedes albopictus cells grown in L-15 medium supplemented with $5 \%$ fetal bovine serum. The supernatant from infected cells was collected on the 4th day of infection, aliquoted and stored at $-70^{\circ} \mathrm{C}$.

\section{Global transcription analyses}

Samples for RNA isolation were taken from HepG2 cells at 6, 24 and $48 \mathrm{~h}$ after infection with DV or after mock infection. Total RNA was extracted with Trizol (Sigma, USA). Ten micrograms of total RNA was used for CDNA synthesis by incorporating dUTP-Cy3 into the mockinfected cDNA and dUTP-Cy5 into the DV-infected cDNA employing the CyScribe First-Strand cDNA labeling kit (Amersham, USA). Adye-swap experiment was performed for each time point sample. Fluorophore incorporation was analyzed using absorbance at $555 \mathrm{~nm}$ for Cy3 and $655 \mathrm{~nm}$ for Cy5. Equal quantities of labeled cDNA were hybridized using hybridization solution HyblT2 (TeleChem International, Inc., USA) to the collection of a 50-mer oligo human library from MWGBiotech Oligo Sets (Germany). The complete set description of a unique experiment can be found at http://microarrays.ifc.unam.mx/principal.html. Array images were acquired and quantified with a ScanArray 4000 with its accompanying software ScanArray 4000 from Packard BioChips (USA). Data were analyzed with the GenArise software and genes related to the protein synthesis machinery with altered expression ( $Z$ score $\geq 2.0$ or $\leq-2.0$ ) were selected. The complete list of genes covered by microarray and the results of the microarray experiment are available upon request (montero@bioqmed.ufrj.br).

\section{Quantitative real-time PCR}

The relative copy number from selected transcripts of three independent biological samples, infected versus mock-infected, was determined by qRT-PCR analysis to confirm differences of gene expression. Total RNA was extracted and reverse-transcribed using the Taq-Man master mix (Applied Biosystems, USA) following the manufacturer protocol. The cDNA samples were used as templates for amplification of the desired genes by PCR employing the Sybr-Green PCR master mix gene expression assay (Applied Biosystems). The conditions for PCR were: $92^{\circ} \mathrm{C}$ for $2 \mathrm{~min}$, followed by 40 cycles at $92^{\circ} \mathrm{C}$ for $15 \mathrm{~s}, 55^{\circ} \mathrm{C}$ for $30 \mathrm{~s}$, and $72^{\circ} \mathrm{C}$ for $90 \mathrm{~s}$, followed by elongation at $72^{\circ} \mathrm{C}$ for $5 \mathrm{~min}$ and final dissociation at $95^{\circ} \mathrm{C}$ for $15 \mathrm{~s}$. The amount of fluorescence was detected using a 7500 real-time PCR machine (Applied Biosystems). The number of PCR cycles (Ct) required to reach a fluorescence intensity above threshold was calculated using the Sequence detection software version 1.3 (Applied Biosystems) by the standard curve method. Relative expression levels for the studied genes were calculated as described by Ginzinger et al. (30). The measurement of an unrelated control mRNA, GAPDH, was used to normalize the samples. The mean $\mathrm{Ct}$ value for three replicates of each gene was subtracted from the mean $\mathrm{Ct}$ value for three replicates of the reference gene GAPDH in each sample to obtain $\triangle \mathrm{Ct},[(\Delta \mathrm{Ct}=\mathrm{Ct}$ (gene) - Ct (GAPDH)]. Relative copy number (RCN) in the infected HepG2 to uninfected cells was calculated using the following formula: $\mathrm{RCN}=2^{-\Delta \Delta \mathrm{Ct}}$, where $\Delta \Delta \mathrm{Ct}=\Delta \mathrm{Ct}$ (infected) - $\triangle \mathrm{Ct}$ (mock). The primers designed for each gene were: elF4EBP3-f (5'-tggagtgcaagaactcacccattg-3'); elF4EBP3-r (5'-tctgtaactccacatgccaggtca-3'); elF2B2-f (5'-accattggcttctcccgaacagta-3'); elF2B2-r (5'-tggtctt cgtgccaatgatcacct-3'); elF4A1-f (5'-agcagcgagccattc taccttgta-3'); elF4A1-r (5'-tgtagtctcctagtgccatgacca-3'); Denhel-f (5'-cagctgaaatggaggaagcc-3'), Denhel-r (5'-gct atacttgctgggtctgtg-3'); RPs6-f (5-ggcattcctgttacagacc aagga-3'); RPs6-r (5'-acacgtggagtaacaagacgctga-3'); EIF4E-f (5'-tggctagagacacttctgtgcctt-3'), EIF4E-r (5'-tcgatt gcttgacgcagtctccta-3'); EIF4G3-f (5'-accagaagcaagaggag aagccaa-3'), EIF4G3-r (5'-tgtgcaagatgtgaggctgggtat-3'); EIF4G1-f (5'-gaaccacgcaagatcattgccaca-3'), EIF4G1-r (5'-aagttgggctctgaaatggccttc-3'); EIF4B-f (5'-attgaccgtt ccatccttcccact-3'), EIF4B-r (5'-agcaacgtccactcgaatt ctcct-3'); GAPDH-f (5'-tcggagtcaacggatttggtcgta-3'); GAPDH-r (5'-tgatgacaagcttcccgttctcag-3').

\section{Immunoblotting}

HepG2 cells were infected or mock-infected and after 6,24 or $48 \mathrm{~h}$ cells were harvested by centrifugation, resuspended in $0.4 \mathrm{~mL}$ of extraction buffer $(50 \mathrm{mM}$ Tris- $\mathrm{HCl}$, pH 7.5, 50 mM NaF, 1 mM NaVO, $0.2 \%$ Triton X-100, 1 $\mathrm{mM}$ PMSF, $1 \mu \mathrm{g} / \mathrm{mL}$ leupeptin, $1 \mu \mathrm{g} / \mathrm{mL}$ pepstatin, and 1 $\mu \mathrm{g} / \mathrm{mL}$ aprotinin) and homogenized. Extracts were centrifuged at $4^{\circ} \mathrm{C}$ for $10 \mathrm{~min}$ at $800 \mathrm{~g}$ and supernatants were collected. Protein concentration was determined by the method of Lowry et al. (31) using bovine serum albumin as standard. Protein samples $(30 \mu \mathrm{g})$ were separated by electrophoresis on a $10 \%$ (for p70S6K) or $12 \%$ (for 4E-BP1) SDS-acrylamide gel using the Mini-Protean II system (BioRad, USA). Electrotransfer of protein from the gel to Immobilon-P was performed for $1 \mathrm{~h}$ and 45 min at $250 \mathrm{~mA}$ per gel in $25 \mathrm{mM}$ Tris, $192 \mathrm{mM}$ glycine and $10 \%$ methanol using a Trans-Blot apparatus (The W.E.P. Company, USA). Membranes were blocked with $5 \%$ non-fat dry milk in Tris-buffered saline for $1 \mathrm{~h}$ at room temperature. Membranes were then incubated overnight at $4^{\circ} \mathrm{C}$ with antibodies against phospho-p70S6K (Thr389), total p70S6K, phospho-4E-BP1 (Thr37/46) and total 4EBP1 (Cell Signaling Technology) and washed. Blots were developed with ECL-plus using peroxidase-conjugated secondary antibodies as indicated by the manufacturer. Protein integrity in the extract and equal loading were confirmed by immunoblot using an antibody against $\beta$-tubulin (Sigma). 


\section{Results}

\section{Transcription analysis of HepG2 cells infected with dengue virus}

We studied the changes with time of gene transcription of HepG2 cells 6, 24, and $48 \mathrm{~h}$ after infection with DV by microarray analysis. After cell collection, the cDNAs relative to transcripts were hybridized against a 50-mer oligonucleotide human library containing 10,000 genes of known function or with homology to them. From this list a set of 41 genes was identified as eukaryotic translation factors and 114 genes corresponded to ribosomal proteins. Genes related to protein translation that were differentially expressed (Z-score $\geq \pm 2.0$ ) at each time relative to control cells were selected. Results showed that $36.5 \%$ of

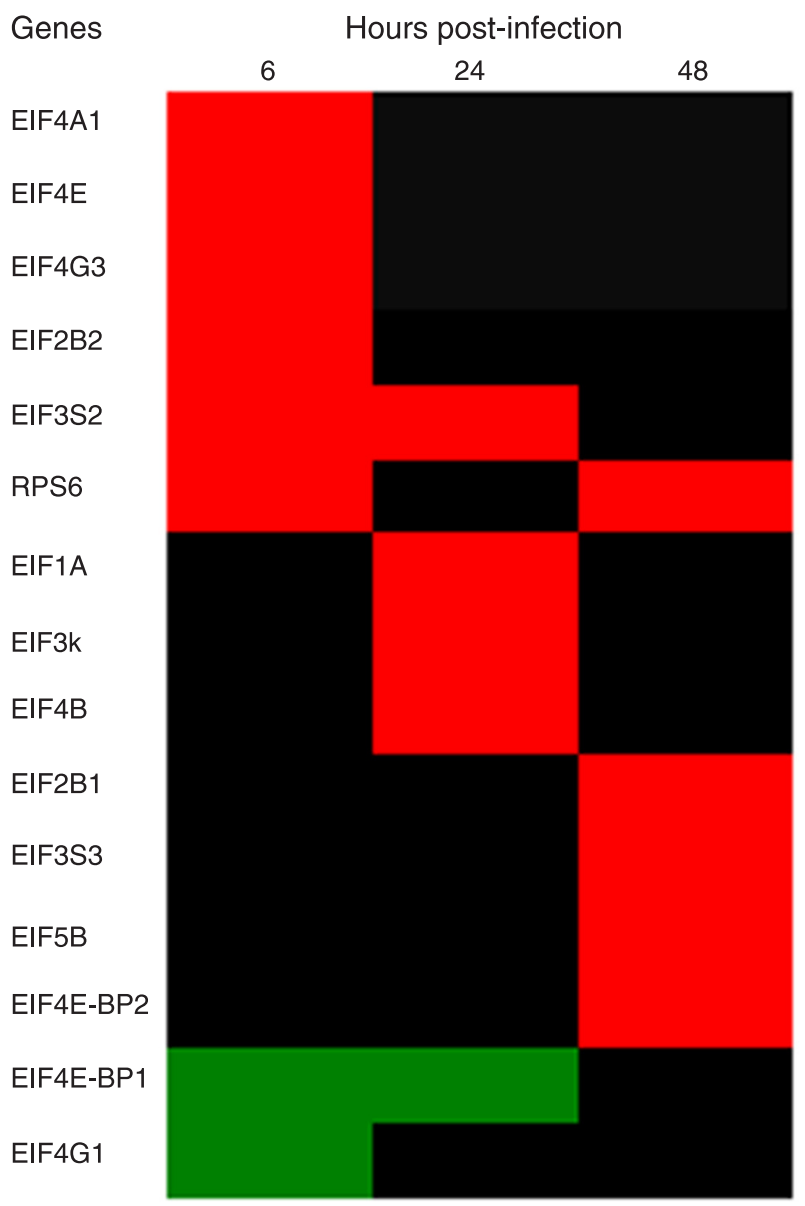

Figure 1. Modification of the expression of genes related to translation and to the target of rapamycin pathway after infection with dengue virus. Alterations in the transcription of genes related to translation are represented. Genes are colored if their corresponding mRNA is up-regulated with a Z-score $\geq 2.0$ (red), down-regulated with Z-score $\geq-2.0$ (green) or with no change (black) at each time of infection. the genes involved in translation initiation and related to activation of mRNA were up-regulated (Figure 1). elF4A1, elF4E, elF4G3, elF3S2, and RPS3A were transiently upregulated at $6 \mathrm{~h}$ post-infection. Also, mTOR, RPS6 and elF4E, genes related to the TOR pathway, which is a positive regulator of translation, were up-regulated at this time. At $24 \mathrm{~h}$ post-infection elF3S2, elF1A, elF3k, and elF4B were up-regulated while RPS6, elF2B1, elF3S3, elF5B, and elF4E-BP2 were down-regulated at $48 \mathrm{~h}$ post-infection. Few genes had their transcription inhibited. elF4E-BP1 was down-regulated during the first $24 \mathrm{~h}$ while elF4G1 was down-regulated only at $6 \mathrm{~h}$ after infection.

In order to confirm the microarray results, we studied differential expression by qRT-PCR under the same conditions as tested in the microarray experiment (Table 1). These genes are essential for the progression of cap-dependent protein synthesis (32). For this purpose we chose six genes that code for proteins that form the elF4F complex, elF4A, elF4E, elF4G1, elF4G3, elF4B, a negative regulator of the formation of the elF4F complex elF4E-BP, and the guanine nucleotide-exchange factor for eukaryotic initiation factor elF2B. The expression of elF4A and elF4G showed a transient up-regulation of transcription at $6 \mathrm{~h}$ post-infection and elF4E-BP3 was down-regulated at this time. At $24 \mathrm{~h}$ post-infection their expression level was equivalent to that of non-infected cells, while interestingly at $48 \mathrm{~h}$ post-infection the genes assayed were down-regulated except for elF4E (Table 1). It should also be noted that the elF4B gene was highly expressed (6 times of induction) at $6 \mathrm{~h}$ of infection. elF4B protein is particularly important for modulating protein synthesis and has been shown to be positively regulated by phosphorylation by its interaction with elF3 (33). Transcription of elF4E-BP3, which is a negative regulator of protein synthesis $(34,35)$, was inhibited at $6 \mathrm{~h}$ post-infection, when measured by qRT-PCR, as well as EIF4E-BP1 shown in the microarray experiment. This indicates that $D V$ is favoring cap-dependent translation. However, at $48 \mathrm{~h}$ of infection elF4E-BP3 was also down-regulated, a fact that is not consistent with our hypothesis that cap-dependent translation is inhibited at $48 \mathrm{~h}$ of infection. Until now elF4E-BP has not been shown to be regulated at the transcription level, but the role of its phosphorylation state in the regulation of general protein translation has been extensively studied (35). Thus, the transcription levels of RPS6, a positive regulator of cap-dependent translation, was measured as also was the phosphorylation of elF4E-BP and of the positive regulator of cap-dependent translation, p70S6K.

\section{DV infection leads to regulation of $\mathrm{p70} 6 \mathrm{~K}$ and 4E-BP1 phosphorylation}

RPS6 is phosphorylated by p70S6K and this event is correlated with activation of protein synthesis and cell growth (13). qRT-PCR results showed that the corresponding gene for RPS6 is up-regulated (1.85 \pm 0.30 -fold) after $6 \mathrm{~h}$ of infection in relation to the mock-infected control, and 
Table 1. 4E-BP1 phosphorylation is modified by dengue virus infection.

\begin{tabular}{lccc}
\hline & \multicolumn{3}{c}{ Time post-infection } \\
\cline { 2 - 4 } & $6 \mathrm{~h}$ & $24 \mathrm{~h}$ & $48 \mathrm{~h}$ \\
\hline elF4A & $1.39 \pm 0.22$ & $0.74 \pm 0.10$ & $0.71 \pm 0.11$ \\
elF4E & $1.17 \pm 0.42$ & $0.75 \pm 0.13$ & $1.15 \pm 0.35$ \\
elF4G1 & $1.66 \pm 0.30$ & $0.93 \pm 0.26$ & $0.61 \pm 0.25$ \\
elF4G3 & $0.99 \pm 0.23$ & $0.98 \pm 0.30$ & $0.61 \pm 0.22$ \\
elF4B & $1.43 \pm 0.20$ & $1.21 \pm 0.40$ & $0.34 \pm 0.17$ \\
elF4E-BP3 & $0.77 \pm 0.20$ & $1.30 \pm 0.21$ & $0.66 \pm 0.10$ \\
elF2B2 & $1.01 \pm 0.19$ & $1.07 \pm 0.33$ & $0.64 \pm 0.10$ \\
RPS6 & $1.85 \pm 0.35$ & $0.52 \pm 0.18$ & $0.71 \pm 0.09$ \\
\hline
\end{tabular}

Quantitative real-time PCR (qRT-PCR) experiments were carried out to measure mRNA expression of the indicated genes. Specific primers were designed for each gene and cDNAs synthesized using RNA isolated from HepG2 cells mock-infected or infected with dengue virus after 6,24 , and $48 \mathrm{~h}$ were used as templates. GAPDH expression was used to normalize the results. The average relative copy number (infected/mock-infected samples) obtained from three independent experiments carried out in triplicate $\pm S D$ is reported.

down-regulated, $0.52 \pm 0.18$ and $0.71 \pm 0.09$, at 24 and 48 $h$, respectively (Table 1 ). This result confirms the fact that protein synthesis is activated during initial times of infection. To further evaluate this result, we have studied the changes induced in the phosphorylation state of p70S6K after 6 , 24 and $48 \mathrm{~h}$ of DV infection and compared them to control mock-infected cells. The antibody to total p70S6K showed that the expression of p70S6K was not influenced by DV infection (Figure 2A, upper panel) while the antibody against p70S6K phosphorylated at T389 (P-Thr-389), showed that $\mathrm{p} 70 \mathrm{~S} 6 \mathrm{~K}$ continued to be phosphorylated in the $6 \mathrm{~h}$ of infection like control cells (Figure 2, middle panel), while dephosphorylation was induced as infection progressed (24 and $48 \mathrm{~h}$ ).

Another protein that has been involved in the regulation of cap-dependent translation via the TOR and AKT pathways is the regulatory factor, 4E-BP1. Treatment of cells with insulin or growth factors induces 4E-BP1 phosphorylation, while its dephosphorylation by stress results in protein synthesis inhibition $(10,11)$. The data for qRT-PCR indicated repression of transcription of the subunit elF4EBP3 at 6 and $48 \mathrm{~h}$ post-infection, while no alteration was detected at $24 \mathrm{~h}$ (Table 1). In this experiment, we expected to observe down-regulation also at $24 \mathrm{~h}$. We decided to directly assay the state of 4E-BP1 phosphorylation during infection by Western blot using a polyclonal anti-4E-BP1 antibody or a phosphospecific antibody (P-Thr-37/46). We observed both differential expression and phosphorylation patterns induced by DV infection. In control cells, two main proteins of 20 and $18 \mathrm{kDa}$ were visualized with the total
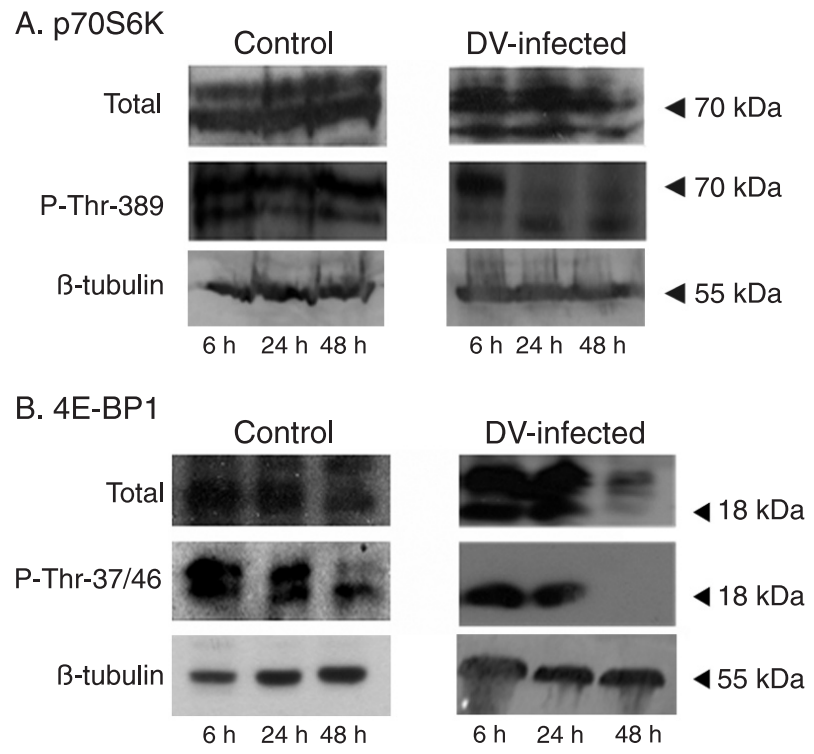

Figure 2. p70S6K and 4E-BP1 phosphorylation is modified by dengue virus (DV) infection. Whole cell protein extracts from HepG2 cells infected with DV, or mock-infected for 6, 24 or 48 $\mathrm{h}$, were prepared and $30 \mu \mathrm{g}$ protein was analyzed by Western blot. Panel A, Western blot analysis of total p70S6K and its phosphorylated form (P-Thr-389) using specific antibodies. Panel B, Western blot analysis of total 4E-BP1 and its phosphorylated form ( $P$-Thr-37/46). $\beta$-tubulin was used to determine protein integrity in both panels. One representative result is shown of three independent experiments.

antibody and did not change expression throughout the experiment, except for the 18-kDa protein whose expression was down-regulated. On the other hand, DV induced reduced expression of both proteins at $48 \mathrm{~h}$ of infection. Regarding phosphorylation, phospho-specific antibodies recognized the two proteins (18 and $20 \mathrm{kDa}$ ) in control cells ( 6 and $24 \mathrm{~h}$ ) while at $48 \mathrm{~h}$ of infection only the $18-\mathrm{kDa}$ protein was observed. In extracts derived from DV-infected cells, only an 18-kDa phosphorylated protein was observed at 6 and $24 \mathrm{~h}$ of infection. As infection progressed no phosphorylated 4E-BP1 was observed, most certainly due to inhibition of its expression. In order to test the integrity of proteins in the extract, we probed the same blots with antibodies against $\beta$-tubulin and the results showed the same intensity of expression throughout the experiment. Taken together, these results show that both p70S6K and 4E-BP1 are phosphorylated at early times of infection, suggesting a cap-dependent translation at this time, which is then inhibited after $24 \mathrm{~h}$ of infection, probably changing to a cap-independent translation.

\section{Discussion}

A strategy used by several virus classes to replicate inside the cell is to halt the host protein synthesis and to 
sequester the protein synthesis machinery for translating their own proteins. However, the flaviviruses are RNA viruses that do not inhibit cellular protein synthesis. The structure of DV RNA resembles typical mRNA with a 5'cap structure. However, DV RNA is differentiated because it contains a 3'UTR, which forms a stalk structure resembling the poly $(A)$ tail (36). This structure suggests that DV utilizes the cap-dependent translation machinery for protein synthesis. However, it has been shown that DV can utilize an alternative mechanism independent of an internal ribosome entry site that might depend on the interaction between the 5 ' and 3'UTR for binding to the initiation factors (37). Until now, no study has been done on the interaction of DV with the cap-dependent machinery of the host cell. As a first approach, we analyzed differentially expressed genes post-infection using an oligo-library containing 10,000 of approximately 25,000 genes coded by the human genome. This library was chosen because it contains only genes with known or predicted function. We focused our analyses on the genes related to translation. It is noteworthy that of the 10,000 genes analyzed, 41 represent translation factors, and of these genes with changed expression, a cluster related to protein synthesis was up-regulated in response to DV at an early time of infection (6 h). In contrast to our results, another study that monitored the transcriptional response to DV infection in HepG2 cells did not detect significant differential expression of genes related to protein synthesis from 3 to $72 \mathrm{~h}$ of infection (38). Using qRT-PCR methodology, we tested eight genes related to the initiation of translation. It should be noted that all of them are positive factors needed for protein synthesis except for elF4E-BP3 that is part of elF4E-BP, which in its dephosphorylated form inhibits elF4E assembly into the elF4F complex. At 24 and $48 \mathrm{~h}$ of infection all of them were down-regulated. Inhibition of crucial translation factors by DV infection and the studied independence of DV on cap-dependent translation led us to examine whether infection would modulate 4EBP-1 and p70S6K phosphorylation. A key aspect of regulation of protein translation is the phosphorylation state of 4EBP-1

\section{References}

1. Guzman MG, Kouri G. Dengue: an update. Lancet Infect Dis 2002; 2: 33-42.

2. Mackenzie JS, Gubler DJ, Petersen LR. Emerging flaviviruses: the spread and resurgence of Japanese encephalitis, West Nile and dengue viruses. Nat Med 2004; 10: S98S109.

3. Whitehead SS, Blaney JE, Durbin AP, Murphy BR. Prospects for a dengue virus vaccine. Nat Rev Microbiol 2007; 5: 518528.

4. Clyde K, Kyle JL, Harris E. Recent advances in deciphering viral and host determinants of dengue virus replication and pathogenesis. J Virol 2006; 80: 11418-11431.

5. Hershey JWB, Merrick WC. The pathway and mechanism and $\mathrm{p} 70 \mathrm{S6K}$. Both phosphorylated proteins induce cell proliferation and protein synthesis and their phosphorylation is inhibited by rapamycin and wortmanin, which inhibit the mTOR and AKT pathways. Our results showed that at an early time of infection with DV, p70S6K and 4E-BP1 are phosphorylated. However, the progression of infection in HepG2 cells leads to dephosphorylation of both proteins, which may be related to an inhibition of cap-dependent protein synthesis.

In studies using picornavirus models, it has been shown that poliovirus and encephalomyocarditis virus shut off protein synthesis and a primary event is the dephosphorylation of 4E-BP1 leading to inhibition of cap-dependent translation (39). Furthermore, DV does not rely on capdependent protein synthesis, since the addition of wortmanin or LY294002 does not inhibit virus translation (17). On the basis of the results obtained, we propose a model whereby DV enters HepG2 cells and replicates through a cap-dependent translation during the first hours of infection and then switches to a cap-independent translation as seen by inhibition of transcription of translation initiation factors and dephosphorylation of 4E-BP1 and p70S6K. It would be interesting now to determine which initiation factors are required for translation of DV proteins by the cap-independent mechanism, since a potential selective advantage for the DV involving a switch from cap-dependent to cap-independent protein translation mechanisms would be to have a lower requirement for initiation factors that might be rate limiting in the cell. Another selective advantage would be to bypass apoptosis induced by the virus (40), which can promote inhibition of host cap-dependent protein synthesis.

\section{Acknowledgments}

We thank José Luis Santillán Torres and Lorena Chávez González, Microarray Unit, Instituto de Fisiologia Celular, Universidad Nacional Autónoma de México, for technical support. of initiation of protein synthesis. In: Sonenberg N, Hershey JWB, Mathews MB (Editors), Translational control of gene expression. Cold Spring Harbor: Cold Spring Harbor Press; 2000. p 33-88.

6. Sachs $A B$, Varani G. Eukaryotic translation initiation: there are (at least) two sides to every story. Nat Struct Biol 2000; 7: 356-361.

7. Jones RM, Branda J, Johnston KA, Polymenis M, Gadd M, Rustgi $A$, et al. An essential $E$ box in the promoter of the gene encoding the mRNA cap-binding protein (eukaryotic initiation factor $4 \mathrm{E}$ ) is a target for activation by c-myc. Mol Cell Biol 1996; 16: 4754-4764.

8. Sonenberg N, Gingras AC. The mRNA 5' cap-binding protein 
elF4E and control of cell growth. Curr Opin Cell Biol 1998; 10: $268-275$

9. Burnett PE, Barrow RK, Cohen NA, Snyder SH, Sabatini DM. RAFT1 phosphorylation of the translational regulators p70 S6 kinase and 4E-BP1. Proc Natl Acad Sci U S A 1998; 95: 1432-1437.

10. Martin-Perez J, Thomas G. Ordered phosphorylation of $40 \mathrm{~S}$ ribosomal protein $\mathrm{S} 6$ after serum stimulation of quiescent 3T3 cells. Proc Natl Acad Sci U S A 1983; 80: 926-930.

11. Fingar DC, Richardson CJ, Tee AR, Cheatham L, Tsou C, Blenis J. mTOR controls cell cycle progression through its cell growth effectors S6K1 and 4E-BP1/eukaryotic translation initiation factor 4E. Mol Cell Biol 2004; 24: 200-216.

12. Chung J, Grammer TC, Lemon KP, Kazlauskas A, Blenis J. PDGF- and insulin-dependent pp70S6k activation mediated by phosphatidylinositol-3-OH kinase. Nature 1994; 370: 7175.

13. Sonenberg N, Pelletier J. Poliovirus translation: a paradigm for a novel initiation mechanism. Bioessays 1989; 11: 128132.

14. Gradi A, Svitkin YV, Imataka H, Sonenberg N. Proteolysis of human eukaryotic translation initiation factor elF4GII, but not elF4GI, coincides with the shutoff of host protein synthesis after poliovirus infection. Proc Natl Acad Sci U S A 1998; 95: 11089-11094.

15. Holden KL, Harris E. Enhancement of dengue virus translation: role of the 3' untranslated region and the terminal 3 stem-loop domain. Virology 2004; 329: 119-133.

16. De Nova-Ocampo M, Villegas-Sepulveda N, del Angel RM. Translation elongation factor-1alpha, La, and PTB interact with the 3' untranslated region of dengue 4 virus RNA. Virology 2002; 295: 337-347.

17. Edgil D, Polacek C, Harris E. Dengue virus utilizes a novel strategy for translation initiation when cap-dependent translation is inhibited. J Virol 2006; 80: 2976-2986.

18. Seneviratne SL, Malavige GN, de Silva HJ. Pathogenesis of liver involvement during dengue viral infections. Trans $R$ Soc Trop Med Hyg 2006; 100: 608-614.

19. Couvelard A, Marianneau P, Bedel C, Drouet MT, Vachon F, Henin D, et al. Report of a fatal case of dengue infection with hepatitis: demonstration of dengue antigens in hepatocytes and liver apoptosis. Hum Pathol 1999; 30: 1106-1110.

20. Bhamarapravati N. Hemostatic defects in dengue hemorrhagic fever. Rev Infect Dis 1989; 11 (Suppl 4): S826S829.

21. Huerre MR, Lan NT, Marianneau P, Hue NB, Khun H, Hung NT, et al. Liver histopathology and biological correlates in five cases of fatal dengue fever in Vietnamese children. Virchows Arch 2001; 438: 107-115.

22. Mohan B, Patwari AK, Anand VK. Hepatic dysfunction in childhood dengue infection. J Trop Pediatr 2000; 46: 4043.

23. Kuo CH, Tai DI, Chang-Chien CS, Lan CK, Chiou SS, Liaw YF. Liver biochemical tests and dengue fever. Am J Trop Med Hyg 1992; 47: 265-270.

24. Nguyen TL, Nguyen TH, Tieu NT. The impact of dengue haemorrhagic fever on liver function. Res Virol 1997; 148: 273-277.

25. Wahid SF, Sanusi S, Zawawi MM, Ali RA. A comparison of the pattern of liver involvement in dengue hemorrhagic fever with classic dengue fever. Southeast Asian J Trop Med Public Health 2000; 31: 259-263.

26. Subramanian V, Shenoy S, Joseph AJ. Dengue hemorrhagic fever and fulminant hepatic failure. Dig Dis Sci 2005; 50: $1146-1147$

27. Knowles BB, Howe CC, Aden DP. Human hepatocellular carcinoma cell lines secrete the major plasma proteins and hepatitis B surface antigen. Science 1980; 209: 497-499.

28. Kosaki A, Webster NJ. Effect of dexamethasone on the alternative splicing of the insulin receptor mRNA and insulin action in HepG2 hepatoma cells. J Biol Chem 1993; 268: 21990-21996.

29. Chen Q, Xia Y, Qiu Z. Effect of ecdysterone on glucose metabolism in vitro. Life Sci 2006; 78: 1108-1113.

30. Ginzinger DG, Godfrey TE, Nigro J, Moore DH, Suzuki S, Pallavicini MG, et al. Measurement of DNA copy number at microsatellite loci using quantitative PCR analysis. Cancer Res 2000; 60: 5405-5409.

31. Lowry $\mathrm{OH}$, Rosebrough NJ, Farr AL, Randall RJ. Protein measurement with the Folin phenol reagent. J Biol Chem 1951; 193: 265-275

32. Pestova TV, Kolupaeva VG. The roles of individual eukaryotic translation initiation factors in ribosomal scanning and initiation codon selection. Genes Dev 2002; 16: 29062922.

33. Shahbazian D, Roux PP, Mieulet V, Cohen MS, Raught B, Taunton J, et al. The mTOR/PI3K and MAPK pathways converge on elF4B to control its phosphorylation and activity. EMBO J 2006; 25: 2781-2791.

34. Pause A, Belsham GJ, Gingras AC, Donze O, Lin TA, Lawrence JC Jr, et al. Insulin-dependent stimulation of protein synthesis by phosphorylation of a regulator of 5'-cap function. Nature 1994; 371: 762-767.

35. Richter JD, Sonenberg N. Regulation of cap-dependent translation by elF4E inhibitory proteins. Nature 2005; 433: 477-480.

36. Chambers TJ, Hahn CS, Galler R, Rice CM. Flavivirus genome organization, expression, and replication. Annu Rev Microbiol 1990; 44: 649-688.

37. Edgil D, Harris E. End-to-end communication in the modulation of translation by mammalian RNA viruses. Virus Res 2006; 119: 43-51.

38. Fink J, Gu F, Ling L, Tolfvenstam T, Olfat F, Chin KC, et al. Host gene expression profiling of dengue virus infection in cell lines and patients. PLoS Negl Trop Dis 2007; 1: e86.

39. Gingras AC, Svitkin Y, Belsham GJ, Pause A, Sonenberg N. Activation of the translational suppressor 4E-BP1 following infection with encephalomyocarditis virus and poliovirus. Proc Natl Acad Sci U S A 1996; 93: 5578-5583.

40. Thongtan T, Panyim S, Smith DR. Apoptosis in dengue virus infected liver cell lines HepG2 and Hep3B. J Med Virol 2004; 72: 436-444. 